\title{
The Role of the Host Defense System in the Development of Cerebral Vasospasm: Analogies between Atherosclerosis and Subarachnoid Hemorrhage
}

\author{
Hiroji Yanamoto ${ }^{a-c}$ Hiroharu Kataoka ${ }^{b}$ Yukako Nakajo ${ }^{a, c, d}$ Koji liharab \\ a Laboratory of Neurology and Neurosurgery, ${ }^{\mathrm{b}}$ Department of Neurosurgery, National Cerebral and Cardiovascular \\ Research Center, Suita, 'Division of Surgical Medicine, Department of Cardiovascular Science, Osaka University \\ Graduate School of Medicine, Suita, and ${ }^{\mathrm{d}}$ Research Laboratories, Rakuwa-kai Otowa Hospital, Kyoto, Japan
}

\section{Key Words}

Platelet-derived growth factor-BB · Cerebral vasospasm •

Subarachnoid hemorrhage $\cdot$ Complement system .

Thrombin · Atherosclerosis

\begin{abstract}
Similar to atherosclerosis, platelet-derived growth factor (PDGF)-BB, a major growth factor for vascular smooth muscle cells, is produced in arterial walls to repair arteries after subarachnoid hemorrhage (SAH). On review of a series of research articles that focus on defensive host responses to SAH, PDGF-BB is identified as a spasmogen, based on the following findings: (1) foreign substances injected into the subarachnoid space cause persistent constriction of cerebral arteries with a time course and histological features almost identical to those seen after SAH; (2) persistent constriction induced by SAH or a foreign substance is dependent on the complement system; (3) the complement system, which stimulates platelets, macrophages and endothelial cells to secrete PDGF-BB, is activated in both the cerebrospinal fluid (CSF) and plasma immediately after SAH; (4) PDGF-BB levels in the CSF are significantly elevated in patients with delayed cerebral ischemia; (5) the immunodensity of PDGF-BB in the arterial walls correlates well with the severity of cerebral vasospasm; (6) intracisternal injection of PDGF-BB induces per-
\end{abstract}

sistent constriction of cerebral arteries in a dose-dependent manner; (7) prolonged contact with blood clots promotes the contractile response of cerebral arteries to PDGF-BB, and (8) administration of an antagonist of PDGF-BB function suppresses the development of cerebral vasospasm.

Copyright $\odot 2012$ S. Karger AG, Basel

\section{Introduction}

Despite tremendous laboratory and clinical research efforts for half a century, cerebral vasospasm, i.e. delayed and persistent contraction of the cerebral arteries, which arises mostly between 4 and 12 days after subarachnoid hemorrhage (SAH), still remains a major cause of delayed cerebral ischemia (DCI; delayed ischemic symptoms or cerebral infarction due to cerebral vasospasm) and morbidity [1-4].

Investigations into the etiology of cerebral vasospasm began with the concept that cerebral vasospasm is a state of progressive increase in vascular tone, stimulated by a potent vasoconstrictor that originates from the breakdown products of the coagulated blood clot $[5,6]$. Of the blood components, platelet-rich plasma causes persistent vasoconstriction, but to a lesser extent than that seen after whole-blood injection $[7,8]$. Because a cisternal injec-

\section{KARGER}

Fax +4161306 1234 E-Mail karger@karger.ch www.karger.com (c) 2012 S. Karger AG, Basel

0014-3022/12/0686-0329\$38.00/0

Accessible online at:

www.karger.com/ene
Hiroji Yanamoto, MD, DMSc

Laboratory of Neurology and Neurosurgery

National Cerebral and Cardiovascular Research Center

5-7-1 Fujishiro-dai, Suita, Osaka 565-8565 (Japan)

Tel. +81 66833 5012, E-Mail hyanamot@ res.ncvc.go.jp 
tion of intact erythrocytes, but not hemolysate, caused persistent contraction of cerebral arteries $[9,10]$, slow lysis of the coagulated clot that permits continuous release of oxy-hemoglobin (oxy-Hb), a candidate vasoconstrictor in the hemolysate, was considered essential in the development of cerebral vasospasm $[5,9]$.

However, relatively slow lysis rates of subarachnoid clots (i.e. a clot clearance rate on CT of $\leq 19 \% /$ day) were not associated with a risk of DCI [11]. The contractile response of rabbit basilar artery to purified oxy-Hb was significantly weak [12]. In addition, the concentration of oxy-Hb in the cerebrospinal fluid (CSF) from SAH patients was, if anything, inversely associated with the maximal constricting activities of canine basilar arteries [13].

Later, it was newly hypothesized that endothelin-1, a potent vasoconstrictor of cerebral arteries produced from endothelial cells or vascular smooth muscle cells (VSMCs) by stimulation with oxy-Hb, was the spasmogen [14]. Accumulating pro and contra evidence related to endothelin-1 [14-18], in a phase II randomized clinical trial (RCT) of clazosentan, a selective endothelin A receptor antagonist, it was found that clazosentan significantly reduced the incidence of 'moderate to severe ( $<67 \%$ of control) vasospasm on the angiogram', from $88 \%$ in placebo-treated individuals to $40 \%$ in the treated group $(n=32)$ [19]. However, the results of the latest phase III RCT $(n=1,157)$ did not demonstrate a beneficial effect of the drug in patients with SAH as regards functional outcome, vasospasm-related morbidity or mortality. The primary endpoint, including all-cause mortality, DCI and rescue therapy for vasospasm, was met in 161 of 764 clazosentan-treated patients (21\%) and 97 of 383 placebo-treated patients (25\%; relative risk reduction $17 \%, 95 \%$ confidence interval -4 to $33 \%$; $\mathrm{p}=$ 0.10 ). Poor functional outcome (extended Glasgow outcome scale score $\leq 4$ ) occurred in 224 clazosentan-treated patients (29\%) and 95 placebo-treated patients (25\%; relative risk reduction $-18 \%, 95 \%$ confidence interval -45 to $4 \% ; p=0.10$ ) [20]. In terms of the factors that aggravate functional outcome, 290 (38\%) clazosentantreated patients and $134(35 \%)$ placebo-treated patients had a new or worsened cerebral infarction (all causes) 6 weeks after SAH. In addition, pneumonia, hypotension, and pleural or pulmonary edema were also more common in the clazosentan-treated group [20]. These observations suggest that clazosentan dilates not only cerebral arteries in vasospasm, but also (systemic) normal arteries. In this regard, the investigators discussed that the effect of oral nimodipine, a calcium blocker and a potent vasodilator, used in combination with clazosen- tan in about four-fifths of patients, needed further analysis (on its contribution to increased incidences of hypotension and the other adverse events) [20]. It is also possible that the drug affected endothelial cell functions to increase vascular permeability, which causes pleural or pulmonary edema. Furthermore, anemia, an etiologic factor of hypotension and an enhancer of ischemic complications in various organs, occurred in $21 \%$ of clazosentan-treated patients but in $14 \%$ of placebo-treated patients (relative risk increase 50\%) [20]. Given these unexpected side effects related to increased vascular permeability, nonspecific vasodilation and enhanced breakdown of erythrocytes, the superiority of systemically administered clazosentan to placebo was not demonstrated by the RCT protocol.

In the continuing journey to find the spasmogen, instead of searching for vasoconstrictors or vasodilators that immediately alter arterial tone under normal conditions, biological host defense/repair cascades in the subarachnoid space have been studied intensively, although a reliable spasmogen that acts as an intermediary, produced in the inflammatory cascade, was not found for a long time [3, 21-25].

On review and organization of evidence related to the host defense/repair cascades that occur in response to extravascular clot formation, we here propose a theory that implicates a growth factor in the development of cerebral vasospasm. Platelet-derived growth factor (PDGF)-BB, which essentially repairs damaged arteries, fulfills the qualifications for a spasmogen. Interestingly, arterial responses to bleeding or injury resemble the biological responses that occur in the pathophysiology of atherosclerosis [26-30].

\section{The Physiological Function of PDGF}

PDGF exists as a homo- or heterodimer with $\mathrm{A}, \mathrm{B}, \mathrm{C}$ or $\mathrm{D}$ chains, i.e. PDGF-AA, $-\mathrm{AB},-\mathrm{BB},-\mathrm{CC}$ or -DD $[31,32]$. In the PDGF family, PDGF-BB, secreted from platelets, activated monocytes/macrophages and endothelial cells, is a proliferation-promoting factor for VSMCs [33].

Upregulation of PDGF is induced by a variety of stimuli, including hypoxia/ischemia, contact with thrombin and stimulation by cytokines or growth factors that include PDGF itself $[29,34]$. The specific receptor for the PDGF B chain, the PDGF $\beta$ receptor (PDGFR- $\beta$ ), can be found in VSMCs, endothelial cells, differentiating (activated) monocytes, fibroblasts, neurons and glial cells [29, 35-39]. Of interest is that after prolonged contact with 
PDGF-BB, the brain develops tolerance to ischemia/infarction [40,41], indicating that PDGF-BB is not only a factor that promotes arterial repair but is also neurotrophic.

Downstream of PDGFR- $\beta$, RhoA protein is upregulated in the membrane fractions of VSMCs, and it in turn activates Rho-associated kinase (ROCK) [42]. In general, the Rho-ROCK pathway modifies cell morphology by controlling actin cytoskeletal architecture. ROCK, as an effecter of upregulated RhoA, plays an important role in promoting cell division of VSMCs. Administration of a selective ROCK inhibitor, Y-27632, prevented proliferation of VSMCs induced by either injury $[43,44]$ or stimulation with PDGF-BB [42]. Arterial injury or production of PDGF-BB thus activates the Rho-ROCK pathway and induces proliferation of VSMCs. PDGF-BB, a promoter of VSMC proliferation, is teleologically a factor that repairs damaged vessels; however, when production is excessive, it could act as an etiologic factor in neointimal formation, atherosclerotic plaque and the formation of other proliferating vascular lesions $[45,46]$.

PDGF-BB also activates the mitogen-activated protein (MAP) kinase pathway [47]. Significantly, the MAP kinase activation induced by PDGF-BB is biphasic, in which a rapid activation phase in mesangial cells at $5-10 \mathrm{~min}$ is followed by a sustained activation phase at $4-6 \mathrm{~h}$ [47]. Although a 30 -min treatment with PDGF-BB is sufficient to induce pronounced de novo synthesis of MAP kinase, for maximal induction of the synthesis of MAP kinase, the presence of PDGF-BB is required for at least $4 \mathrm{~h}$ [47].

\section{The Activated Complement System Stimulates the Production of PDGF-BB}

The complement system is an initiator of the host defense cascade in the fluid phase; this cascade uses multiple serine proteases present in plasma and is activated prior to the cellular defense cascade that employs monocytes, lymphocytes, other inflammatory cells and various cytokines. The final product in the complement system, C5b-9, also termed the membrane attack complex (MAC), stimulates platelets, macrophages and endothelial cells to secrete PDGF-BB $[29,48]$. The activated complement system is thus a trigger of PDGF-BB secretion during the host defense cascade.

Exposure of an artificial surface made of polyvinyl chloride (a foreign substance) to blood components caused broad-spectrum inflammatory responses including activation of the coagulation system and secretion of
PDGF-BB. This response of blood components to a foreign substance is largely dependent on the complement system [49].

\section{Extravascular Bleeding or Arterial Injury Induces the Production of PDGF-BB}

In atherosclerotic plaques, the complement system has been considered an important mediator of unfavorable inflammatory responses. The maturation of atherosclerotic lesions beyond the foam cell (infiltrating macrophages that contain a foamy substance) stage is strongly dependent on activation of the complement system [50]. Upregulated C-reactive protein, a risk factor for atherosclerosis, an indicator of systemic inflammatory responses and a potent activator of the complement system, is colocalized with activated complement components in atherosclerotic plaques [51]. Interestingly, etiologic factors in the development of atherosclerosis, such as modified lipoproteins or cholesterol crystals, foreign substances that trigger the defense cascade, are also potent stimulators of the complement system [28, 30].

Nagata et al. [52] studied the distribution of activated (C5b) and naïve (C5) complement factors and PDGF-BB in human carotid atherosclerotic plaques. They found deposition of activated complement but not the naïve forms of complement in the plaques (fig. 1a). Colocalization of C5b and PDGF-BB, likely a growth cone (a hot spot with actively proliferating VSMCs), was demonstrated at the luminal surface of the plaque (fig. 1a) [52]. The colocalization strongly indicates that PDGF-BB is secreted and/or internalized at the location where the complement system was activated. Regarding the cellular source of PDGF-BB, the PDGF B chain was found in endothelial cells and macrophages in all phases of atherosclerotic lesions $[26,53,54]$.

A synthetic, broad-spectrum serine protease inhibitor, FUT-175 (FUT; nafamostat mesilate), inhibits all the activation pathways in the complement system and the coagulation system. FUT has been approved for the treatment of acute pancreatitis, disseminated intravascular coagulation and shock and is utilized as an anticoagulant during hemodialysis [55-57]. After balloon dilation injury of the rat carotid artery, continuous intravenous FUT administration for 7 days prevented neointimal formation in a dose-dependent manner and also suppressed the production of PDGF-BB [58] (fig. 1b), indicating that the complement system mediates neointimal formation after arterial injury. 

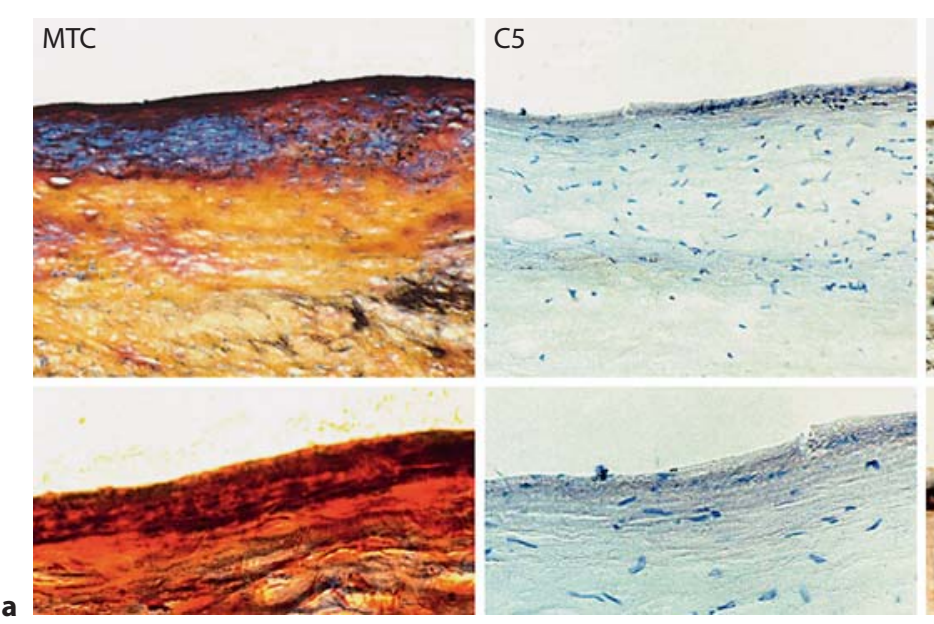

C5b

PDGF-BB

a
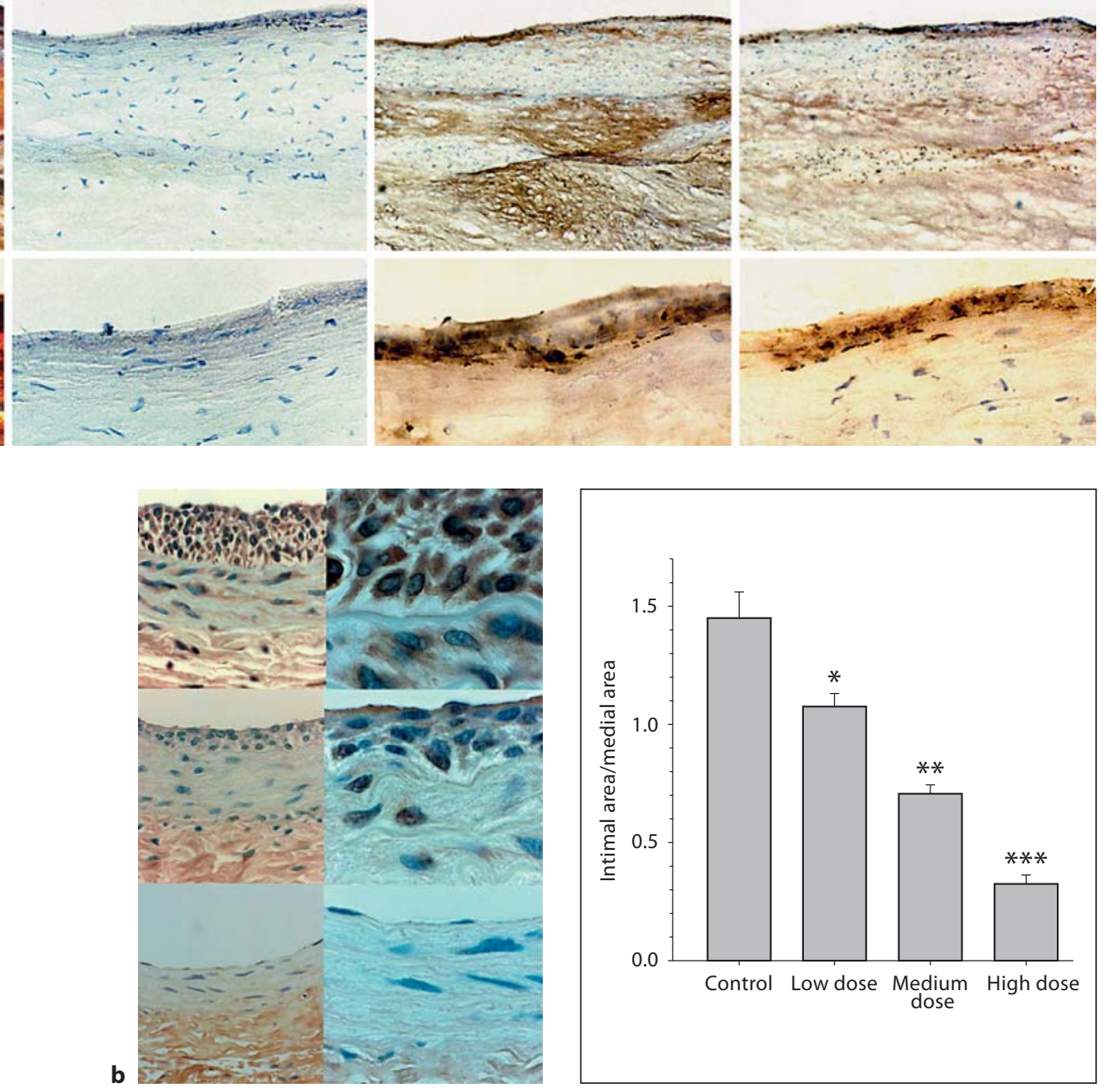

Fig. 1. a Expression of C5, C5b and PDGF-BB in human atherosclerotic plaque. Masson's trichrome (MTC) stains collagen fibers (in the extracellular matrix) blue and muscle fibers (in VSMCs) red. Collagen and living muscle fibers were both detected primarily in the inner layer. Immunoreactivity for the activated form (C5b) but not the inactivated form (C5) of this complement component was detected in the plaque (brown). The innermost area (facing the lumen) that expresses both C5b and PDGF-BB (two right panels) is likely a growth cone. Upper panels: $\times 100$; lower panels: $\times 400$. Modified from Nagata et al. [52]. b PDGF-BB expression after a balloon stretch injury to rat carotid arteries. Upper left panels: neointimal formation 7 days after injury and treat- ment with vehicle alone. Immunoreactivity for PDGF-BB (brown) is demonstrated primarily in the cytoplasm of VSMCs in the intimal and medial cell layers. Middle left panels: suppression of neointimal formation as well as PDGF-BB expression or internalization by treatment with FUT (1 mg/kg i.p. for 7 days). Lower left panels: normal carotid artery without injury. Left panels: $\times 200$; right panels: $\times 600$. Modified from Sawada et al. [58]. The graph shows significant suppression of neointimal formation by intraperitoneal FUT of $0.5,1.0$ or $2.0 \mathrm{mg} /$ day for 7 consecutive days [58]. ${ }^{*} \mathrm{p}<0.05$ compared to medium dose; ${ }^{* *} \mathrm{p}<0.05$ compared to low dose; ${ }^{* *} \mathrm{p}<0.05$ compared to control.
Analysis of the relationship between the amount of $\mathrm{SAH}$ and the development of DCI showed that an increase in the total clot volume on CT increased the risk of DCI [59], and a thick clot that completely filled a cistern or fissure was the best predictor of DCI [1]. However, it was found that perimesencephalic nonaneurysmal SAH seldom caused DCI, but similar SAH distribution and volume from an aneurysmal rupture did [60]. Moreover, elevated mean arterial blood pressure $(>112 \mathrm{~mm} \mathrm{Hg})$ on admission was the most significant independent predic- 

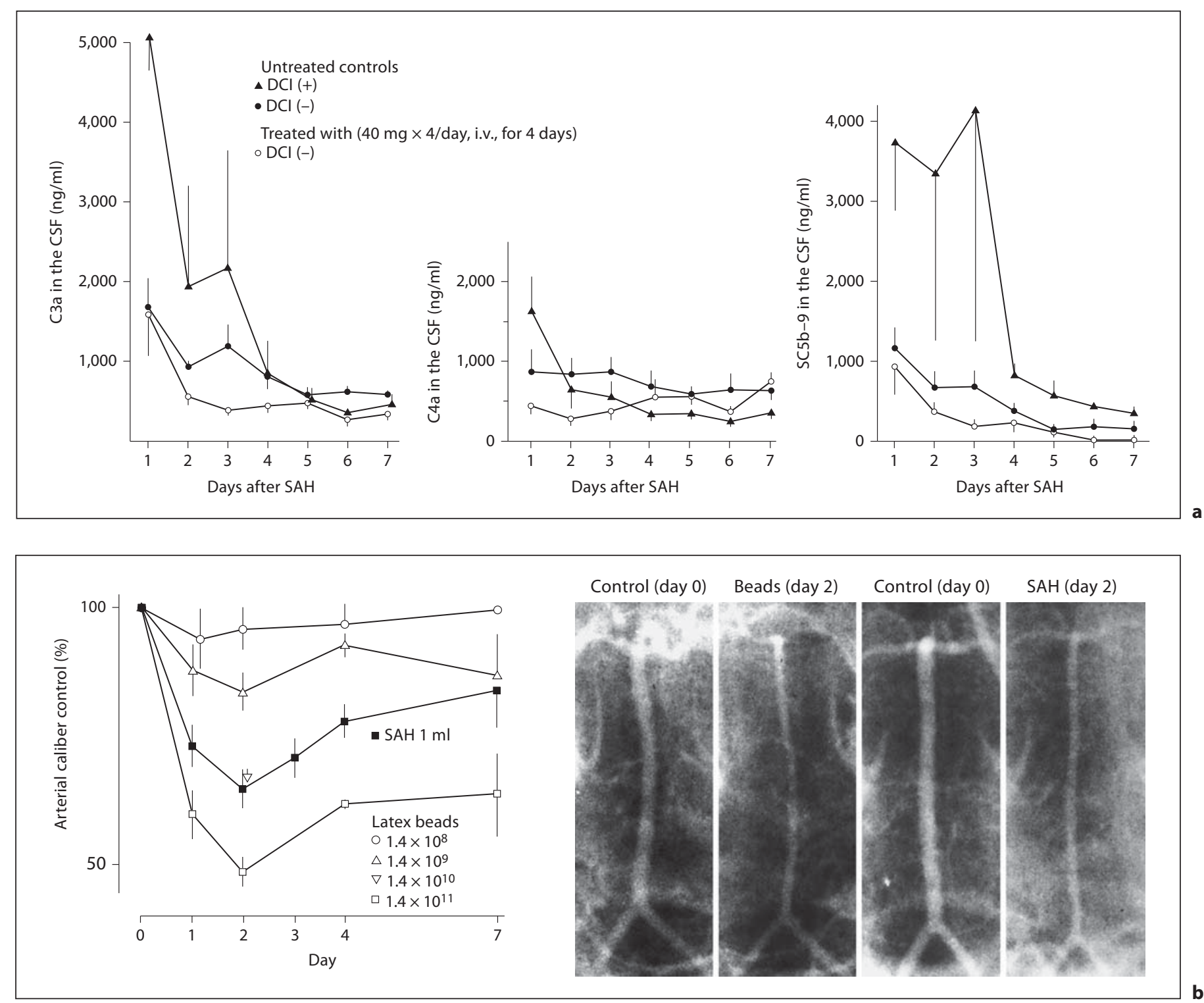

Fig. 2. Levels of complement factors in the CSF of patients with $\mathrm{SAH}(\mathbf{a})$, and alterations in rabbit basilar artery after cisternal injection of a foreign substance (latex beads) or autologous arterial blood (b-d). a C3a and soluble C5b-9 levels in the acute phase were higher in SAH patients with DCI than in those without DCI. The levels of C4a showed no relation to the development of DCI. FUT was administered by intermittent intravenous injection (40 $\mathrm{mg}$ ) every $12 \mathrm{~h}$ for the initial 4 days. Graphs modified from Yana- moto et al. [25]. b The graph shows arterial calibers after cisternal injection of various amounts of latex beads in mock CSF or arterial blood. Slowly progressing, long-lasting vasoconstriction was observed in both instances [24]. Panels: angiograms of rabbit basilar arteries before (control) and $48 \mathrm{~h}$ after the injection of latex beads (two left panels) or after injection of arterial blood (two right panels). tor of DCI among non-CT risk factors [1], indicating that high-pressure arterial bleeding acts as an independent promoter of DCI.

Importantly, high-pressure arterial bleeding has the potential to cause arterial stretching injuries by forming thick hematoma. Because arterial stretching injuries cause PDGF-BB production and internalization in arterial walls (fig. 1b) [58], high-pressure bleeding and thick hematoma-derived arterial injury could be an enhancer of PDGF-BB production and the development of DCI. 
Fig. 2. Levels of complement factors in the CSF of patients with SAH (a), and alterations in rabbit basilar artery after cisternal injection of a foreign substance (latex beads) or autologous arterial blood (b-d). c Basal views of rabbit brain $48 \mathrm{~h}$ after the injection of latex beads (left) or arterial blood (right). The prepontine cistern was packed with latex beads (white) or a thick blood clot (black). d Left panel: electron microscopy revealed that the latex beads induced severe vasoconstriction, which is evident from the corrugation of the internal elastic lamina. Center and right panels: latex beads (center, arrows) or erythrocytes (right, arrows) are phagocytosed by macrophages in the subarachnoid space [24].
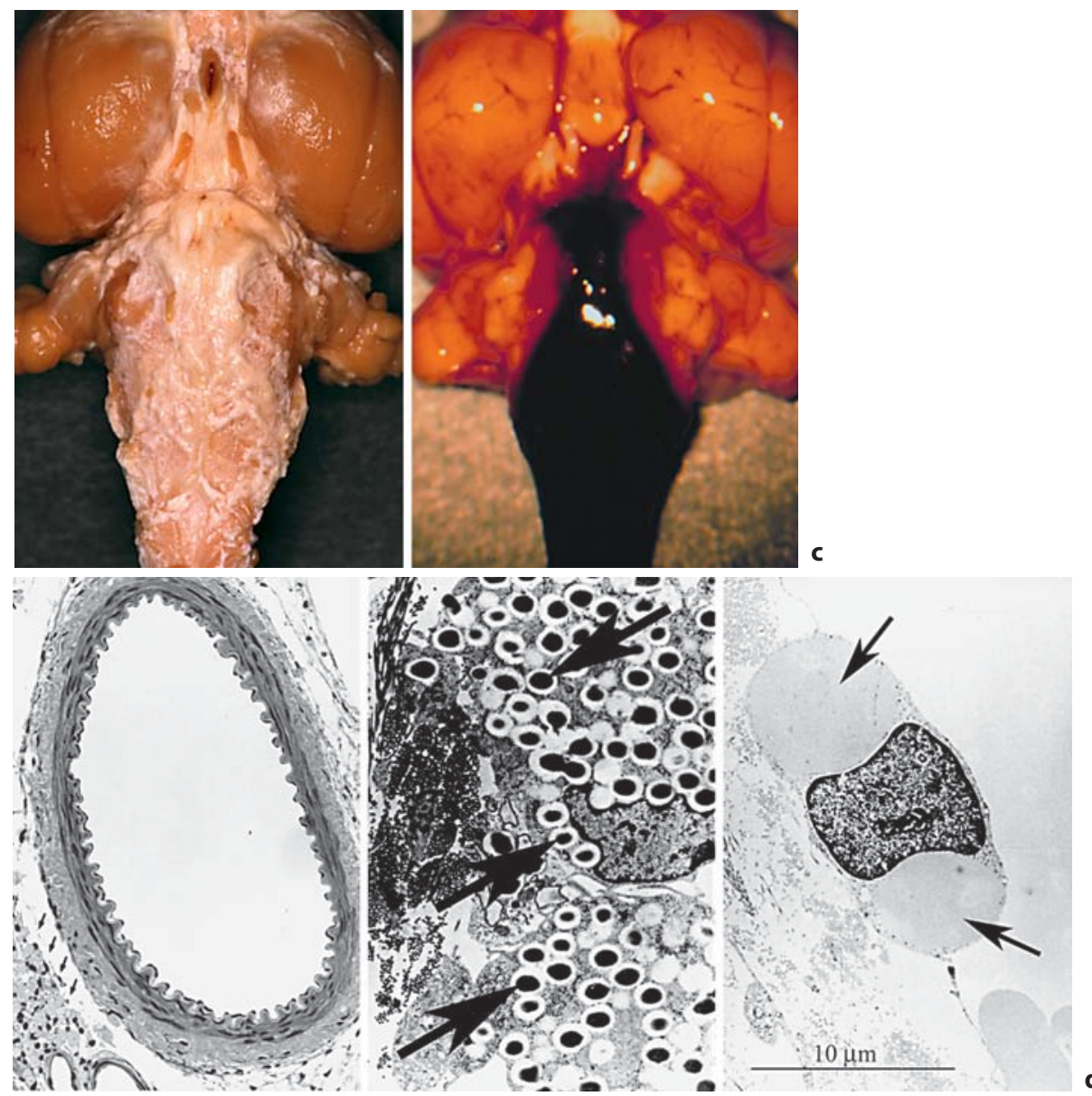

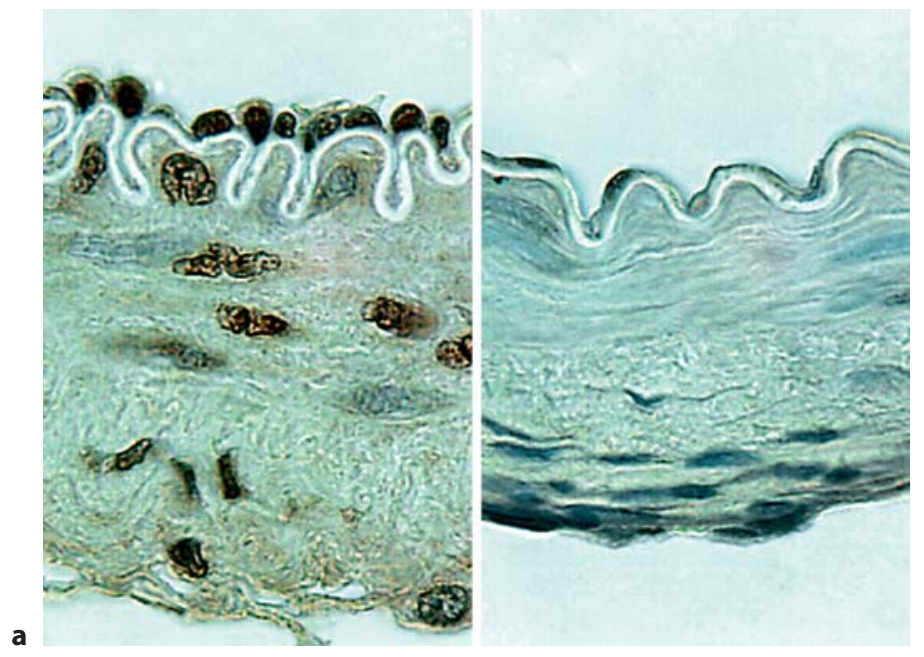

Fig. 3. SAH-induced expression of PDGF-BB (a) and the effect of PDGF-BB injection on the vascular tone of rabbit basilar arteries (b). a On a cross-section of an artery in vasospasm on day 2 after SAH (left panel), endothelial cells, smooth muscle cells and fibroblasts in the adventitial layer express immunoreactivity for PDGF-BB (brown). In contrast, there was no immunostain in the arterial walls under normal conditions without SAH (right pan-

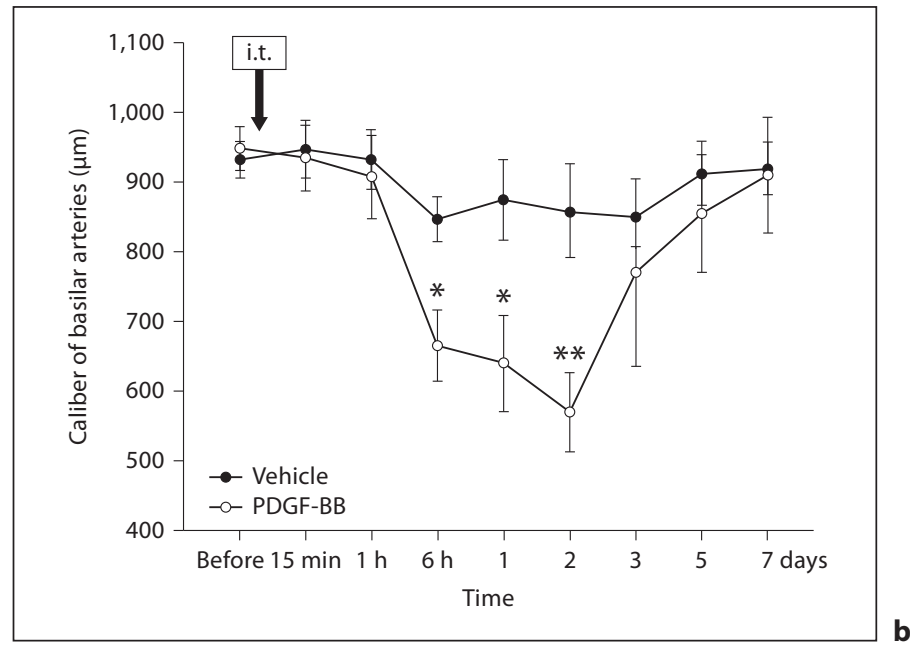

el). Original magnification $\times 600$. Figures modified from Zhang et al. [72]. b Alterations in the caliber of the basilar artery after cisternal (intrathecal, i.t.) injection of recombinant PDGF-BB or vehicle (saline). After injection of PDGF-BB, narrowing developed slowly and lasted for a long duration. ${ }^{*} \mathrm{p}<0.05,{ }^{* *} \mathrm{p}<0.001$ compared to vehicle. From Zhang et al. [77]. 


\section{The Complement System Is Activated in the CSF after SAH}

Of the components of complement, $\mathrm{C} 3 \mathrm{a}$ and $\mathrm{C} 4 \mathrm{a}$, also called anaphylatoxins, were analyzed in the CSF in the acute phase of SAH. C3a but not C4a levels were elevated in patients with DCI compared to those without DCI [25] (fig. 2a). Because C5b-9 (MAC) stimulates macrophages and endothelial cells to upregulate PDGF-BB $[48,54]$, the significant increase in soluble C5b-9 levels in the CSF of patients with DCI suggests that C5b-9 (MAC) was formed on cellular surfaces in the subarachnoid space.

With regard to the complement system in plasma after SAH, Kasuya and Shimizu [61] reported that C3a levels $(<48 \mathrm{~h}$ after SAH) in patients with DCI were significantly higher than in those without DCI. Surprisingly, elevated plasma C3a levels in the acute phase correlated well with unfavorable outcomes in SAH patients and could function as an independent indicator of long-term outcome [62]. In addition to the complement system in the CSF, activation of the complement system in plasma was found as an independent risk factor that enhances the development of DCI.

\section{Stimulation by a Foreign Substance Causes Sustained Contraction of Cerebral Arteries}

To study the role of foreign substance-induced stimulation in the development of cerebral vasospasm, Yanamoto et al. [24] injected into the CSF space of rabbits varying numbers of polystyrene latex beads, spherical ( $1 \mu \mathrm{m}$ in diameter) foreign bodies with negatively charged surfaces, suspended in $1 \mathrm{ml}$ of sterile, artificial CSF or $1 \mathrm{ml}$ of arterial blood (SAH); alterations in the caliber of the basilar artery were then analyzed on angiography. This size of latex bead was known to cause maximal activation of macrophages.

After injection of the beads, the arteries slowly developed long-lasting narrowing, with a similar time course to cerebral vasospasm. The peak contraction increased as the number of latex beads increased, indicating that $1.4 \times 10^{10}$ beads cause arterial narrowing with similar severity to that of cerebral vasospasm (fig. 2b). Histological studies demonstrated that the narrowing is caused by contraction but not proliferation of the arterial walls (fig. 2c). Erythrocytes or latex beads were similarly phagocytosed by macrophages in the subarachnoid space on day 2 [24]. Thus, a foreign substance, not an immediate vasoconstrictor, caused persistent nar- rowing of cerebral arteries similar to cerebral vasospasm.

Besides the beads, sterile talc powder or lipopolysaccharide injected into the CSF space caused delayed and long-lasting narrowing in canine or rabbit basilar arteries. Morphologic, pharmacologic and DCI-like features of the contracted arteries closely resembled those of vasospasm after SAH [63-65].

\section{Characteristics of the Host Defense Cascades in the Development of Cerebral Vasospasm}

Systemic complement depletion by a factor from cobra venom, administered intravenously prior to the induction of SAH, inhibited the development of cerebral vasospasm in rabbits [66]. Intravenous administration of a monoclonal antibody to macrophage antigen-1 (complement receptor 3, CD11b/CD18) inhibited the development of cerebral vasospasm in nonhuman primates [67]. However, steroids (glucocorticoids) that suppress the cellular (lymphocytic) immune system, an immunosuppressant (ciclosporin or FK-506) that suppresses the T cell-mediated immune system and a synthetic protease inhibitor without a potent inhibitory action on the complement system (gabexate mesilate) did not prevent the development of vasospasm in rabbits $[68,69]$.

\section{PDGF-BB Is Detected in the CSF and Arterial Walls after SAH}

Gaetani et al. [70] found that the average PDGF-BB levels in the CSF $(<72 \mathrm{~h})$ after SAH were significantly higher in patients with DCI $(3.9 \mathrm{ng} / \mathrm{ml})$ compared to those without DCI $(1.1 \mathrm{ng} / \mathrm{ml})$. Since PDGF-BB is captured by autologous or bystander cells in an autocrine/ paracrine fashion in the solid phase, platelets or activated monocytes rather than endothelial cells are considered the source of PDGF-BB secretion into the CSF.

Later, Maeda et al. [71], in a tension study, found that prolonged contact with SAH enhances the contractile response of the rabbit basilar artery to PDGF-BB, so that PDGF-BB at $1.0 \mathrm{nmol} / \mathrm{l}(24 \mathrm{ng} / \mathrm{ml})$, i.e. only 6 times higher than the level observed in the CSF of SAH patients with DCI, caused sustained contraction. Regarding the mechanism of SAH-induced enhancement of the arterial response to PDGF-BB, contact stimulation with thrombin or PDGF-BB is known to upregulate PDGFR- $\beta$ in arterial walls (endothelial cells and infiltrated macrophages) [29]. 
In terms of the expression and internalization of PDGF-BB after SAH, strong immunoreactivity for PDGF-BB was observed in endothelial cells, VSMCs and fibroblasts of rabbits, but not in these cells in normal basilar arteries (fig. 3a) [72]. Among PDGF-BB-positive cells in the histology, only endothelial cells can generate PDGF-BB.

\section{Cisternal Injection of PDGF-BB Causes Prolonged Contraction of Cerebral Arteries}

Of the PDGF isomers, PDGF-AA, -AB or -BB induced constriction of aorta $[73,74]$, but none of them was believed to constrict cerebral arteries from the results of ex vivo studies $[75,76]$.

However, Zhang et al. $[72,77]$ found that recombinant PDGF-BB (5-10 $\mu \mathrm{g})$ causes delayed contraction of cerebral arteries in a dose-dependent manner in vivo (fig. 3b). On the other hand, PDGF-AB $(50 \mu \mathrm{g})$ did not cause significant contraction of cerebral arteries in vivo [76], indicating that the PDGF-A and PDGFR- $\alpha$ signal has no contractive property or a lesser one when applied to cerebral arteries, compared with PDGF-BB and PDGFR- $\beta$ signals.

In general, PDGF is known to activate the MAP kinase pathway, the phosphatidylinositol 3-kinase pathway and $\mathrm{Ca}^{2+}$ signaling [78]. As regards PDGF-BB-induced cerebrovascular contraction, Maeda et al. [71] found that the sustained phase of PDGF-BB-induced contraction depended mostly on tyrosine phosphorylation and $\mathrm{Ca}^{2+}$-dependent myosin light chain (MLC) phosphorylation.

Thick blood clots in both lateral ventricles are associated with increased odds for the development of DCI [1], and the volume of cisternal plus intraventricular hemorrhage was a predictor of DCI and functional outcome of SAH patients at 3 months [59]. Thick blood clots in the ventricles may act as an enhancer of contractile responses of cerebral arteries to PDGF-BB by secreting PDGF-BB into the CSF and reducing the clearance of PDGF-BB from the CSF.

\section{Inhibition of Complement Activation Suppresses PDGF-BB Production and the Development of Cerebral Vasospasm}

Yanamoto et al. [79] administered FUT by intermittent intravenous infusion, starting $20 \mathrm{~min}$ after the induction of $\mathrm{SAH}$ in rabbits. The treatment significantly prevented the development of cerebral vasospasm $(2 \mathrm{mg}>3 \mathrm{mg}>$ $1 \mathrm{mg}$, given 12 hourly); however, when FUT was administered after the development of cerebral vasospasm (post hoc) on day 2, there was no suppression of contraction, indicating that the complement system is a mediator of vasospasm but not a vasoconstrictor by itself [79].

When the initial time of intravenous administration of FUT was delayed, from 20 min to 3 or $6 \mathrm{~h}$ after SAH, the effect was reduced by almost half [68]. From the perspective of timing in animals, as described below, the added delay from $20 \mathrm{~min}$ to $3 \mathrm{~h}$ in rabbits is roughly equivalent to extending the delay from 1 to $9 \mathrm{~h}$ in humans.

The persistent contraction induced by latex beads was also prevented by treatment with intermittent intravenous FUT [24], demonstrating that the complement system mediates latex bead-induced persistent contraction.

Using the rabbit SAH model, Zhang et al. [72] administered FUT by a continuous intravenous infusion, starting $40 \mathrm{~min}$ after the induction of SAH. At the peak development of cerebral vasospasm, contraction of the basilar artery was significantly suppressed but to a lesser extent compared with intermittent treatment that increases plasma concentration rapidly in the acute phase [79]. In the histological study, the density of PDGF-BB in the endothelial cells and VSMCs lessened as the volume of FUT increased [72].

In an open clinical study, patients with severe SAH were treated with intermittent intravenous FUT [20 mg $\times 2$ /day, $20 \mathrm{mg} \times 4$ /day or $40 \mathrm{mg} \times 4$ /day for 4 days, starting soon after surgery (performed $<48 \mathrm{~h}$ after $\mathrm{SAH}$ ); $\mathrm{n}=43$ ]. The rate of 'absence of DCI (no DCI development)' increased significantly from $45 \%$ in the controls to $87 \%$ in all the treated groups [80].

Based on these results and the results from a multicenter double-blinded RCT (phase IIa; $\mathrm{n}=71$ ), a phase IIb RCT was performed using intermittent intravenous FUT [40-80 mg/day, or placebo, for the initial 4 days after surgery (performed $<72 \mathrm{~h}$ after $\mathrm{SAH}$ ); $\mathrm{n}=236$; intention to treat (ITT) analysis by Dunnett's test]. However, the results of this study showed an 'absent DCI (on CT)' rate of $66 \%$ in the placebo group, which was no different from the rate of $69 \%$ in the treated group (relative risk reduction $4 \%, \mathrm{p}=0.20$ ). The IIb RCT thus failed to reject the hypothesis that no group has its mean significantly different from the mean of the reference (placebo) group.

However, when comparison was limited to patients in a subgroup that was treated with ozagrel sodium (OZ; OKY-046), a thromboxane A2 synthase (TXA2S) inhibitor, a significant difference was observed in the 'absent $\mathrm{DCI}$ (on CT)' rate of $43 \%$ in the placebo (OZ without FUT) 
group versus $63 \%$ in the treated group (significant $32 \%$ relative risk reduction; $\mathrm{p}=0.02 ; \mathrm{n}=73$ ) [ITT with Dunnett, unpubl. data]. In addition, good functional outcome at 1 month or 3 months was met in 42 , or $58 \%$ in the placebo group versus 57 or $64 \%$ in the FUT-treated group, respectively (relative risk reduction 26 or $14 \% ; \mathrm{p}=0.09$ or $\mathrm{p}=0.32 ; \mathrm{n}=75$ ) [ITT analysis by Dunnett's test; unpubl. data]. Because any addition of drugs to FUT was allowed in the RCT protocol, OZ, which was already approved for the prevention of DCI in Japan, was added in many hospitals according to their institutional protocols. According to the post hoc subgroup analysis, it was demonstrated that FUT has an additive effect to OZ in preventing DCI.

After the RCT, Kaminogo et al. [81] treated patients with severe SAH with intermittent intravenous FUT of $80-160 \mathrm{mg} /$ day for the initial 4 days, in addition to OZ $(n=34)$, the results of which were compared with those of historical controls with OZ monotherapy $(\mathrm{n}=455)$. It was again demonstrated that FUT has an additive effect to $\mathrm{OZ}$ to increase the 'absent DCI' rate and that the therapy improves the clinical outcome at 3 months. They also found that the 'absent DCI' rate was 83\% when FUT therapy was started within $48 \mathrm{~h}$ after SAH but declined to $50 \%$ if started on day 3 or 4 .

\section{Thrombin Also Mediates the Development of Cerebral Vasospasm}

Thrombin, a multifunctional serine protease from the coagulation system that is also a chemotactic factor for monocytes [82], a mitogen for fibroblasts $[83,84]$ and an activator of the complement system, is thought to play an important role in the pathogenesis of cerebral vasospasm $[85,86]$.

Thrombin levels in the CSF of SAH patients in the acute phase correlate with the development of DCI [87], and thrombin causes immediate contraction of arteries [88] by activating the specific thrombin receptor on VSMCs [89]. After SAH, the contractile response of cerebral arteries was markedly enhanced by upregulation of the receptor [90]. However, the peak activation of thrombin in the CSF was earlier (on day 0-4) than the development of DCI [91], similar to the case of complement activation (fig. 2a) [61].

In the rabbit SAH model [79], a continuous intravenous injection of argatroban, a selective thrombin inhibitor, starting $40 \mathrm{~min}$ after the induction of SAH reduced the density of PDGF-BB in the endothelial cells and VSMCs and prevented the development of cerebral vaso- spasm on the angiogram [72]. Recently, Kameda et al. [92] reported that SAH enhances and prolongs the contractile response of the basilar artery to thrombin, and argatroban combined with an antioxidative agent restored the increased response of the basilar artery to thrombin after $\mathrm{SAH}$ in rabbits.

\section{An Antagonist of PDGF-BB Function Suppresses the Development of Cerebral Vasospasm after SAH}

Activation of the Rho-ROCK pathway, which initiates proliferation of VSMCs, was linked to the contractile tone of VSMCs $[93,94]$. Activation of the Rho-ROCK pathway in VSMCs causes vasoconstriction by phosphorylating MLC phosphatase, thus increasing levels of MLC phosphorylation during coronary artery spasm [95]. Indeed, Rho-ROCK was upregulated in rat basilar artery after experimental SAH [96], and topical application of Y-27632 induced dose-dependent dilation of spastic canine basilar arteries [97]. In a canine SAH model, Sasaki et al. [98] reported that p38 MAP kinase was activated in the arterial walls, and administration of a selective MAP kinase inhibitor, FR167653, prevented the development of cerebral vasospasm.

PDGF-BB also causes contraction of a fibroblast-populated collagen matrix by activating both the Rho-ROCK and p38 MAP kinase pathways [99]. Cerebral vasospasm may be associated with alterations in nonmuscle components, such as contraction of myofibroblasts in the collagen matrix. Iwasa et al. [100] showed that just $10 \mathrm{ng} / \mathrm{ml}$ PDGF-BB caused significant compaction of a human myofibroblast-populated collagen lattice, which lasted for more than 3 days in culture. Genetic suppression of procollagen expression, by introducing antisense oligonucleotides, also prevented the development of vasospasm in rats [101].

Trapidil, originally developed as an antiplatelet agent with an inhibitory action on TXA2S [102], has been approved for the treatment of angina pectoris since 1970 in Germany. In a multicenter RCT, trapidil reduced the incidence of cardiovascular and cerebrovascular events in patients with atherosclerosis-associated coronary stenosis $(\mathrm{n}=1,748)$ [103]. Besides its antiplatelet properties, trapidil selectively inhibits PDGF-BB-induced cellular function by inhibiting the MAP kinase pathway at the level of Raf-1 [104] or by modulating the levels of transcription of PDGFR- $\beta$ [105]. Recently, it was found that trapidil inhibits the Rho-ROCK pathway downstream of the PDGFR- $\beta$ signal [106]. 
Suzuki et al. [107] obtained a favorable outcome, with an 'absent DCI' rate of $78 \%$, on treatment with trapidil $(n=20)$ when it was still recognized as a TXA2S inhibitor (an antiplatelet agent). Zhang et al. [77] examined the therapeutic potential of trapidil $(5-30 \mathrm{mg} / \mathrm{kg} /$ day) using the rabbit SAH model [77, 79]. Either starting $1 \mathrm{~h}$ after the induction of SAH (on day 0 ) and continuing for $47 \mathrm{~h}$, or starting after the development of vasospasm (on day 2) and continuing for $30 \mathrm{~min}(3 \mathrm{mg} / \mathrm{kg} / \mathrm{h})$, caliber alterations of the basilar artery were analyzed on angiography.

Continuous prophylactic intravenous administration of trapidil significantly prevented the development of vasospasm in a dose-dependent manner, from $60 \%$ of preSAH baseline values in vehicle to $70-81 \%$ [77]. When trapidil was infused intravenously post hoc for $30 \mathrm{~min}$, vasospasm resolved significantly, at least transiently, solution increasing from 57 to $89 \%$ of the baseline values [77].

\section{The Efficacy of Other Rho-ROCK Pathway Inhibitors in the Prevention of Cerebral Vasospasm}

The Rho-ROCK pathway inhibitor intravenous fasudil hydrochloride (FAS) has been approved for the prevention of DCI in Japan [108-110]. FAS was initially characterized as a calcium antagonist (AT877) [109] but later recognized as a specific Rho kinase inhibitor (HA-1077) [111]. In a multicenter double-blind RCT, FAS improved the 'no cerebral infarction' rate from 62 to $84 \%(n=276$ in total) [109]. In a postmarketing, nonrandomized, surveillance study, the absolute 'no cerebral infarction' rate was $73 \%(\mathrm{n}=2,552$, in a subgroup treated without $\mathrm{OZ})$ or $68 \%(\mathrm{n}=1,138$, in a subgroup treated with OZ) [112]. Post hoc, rapid intravenous or intra-arterial administration of FAS also improved persistent contraction of cerebral vasospasm on the angiogram, but pretreatment levels were almost reached $6 \mathrm{~h}$ after termination of the drug infusion $[77,113]$.

Anei et al. [114] treated patients with SAH with FUT plus FAS, or argatroban plus FAS, and compared the results with those after FAS monotherapy $(\mathrm{n}=105)$. The 'absent DCI' rate improved, although not significantly, from $70 \%$ in the control group to 75 and $81 \%$, respectively [114].

3-Hydroxy-3-methylglutaryl coenzyme A reductase inhibitors, or statins, have revolutionized the management of patients with symptomatic or asymptomatic vascular stenosis, preventing the development of atheroscle- rosis and proliferative vascular lesions [115]. It is well known that the major cardiovascular benefit of statin therapy depends on their inhibitory action on the RhoROCK pathway, independent of their lipid-lowering activities $[93,116]$.

In VSMCs, cerivastatin suppressed PDGF-BB-induced upregulation of RhoA protein in membrane fractions, as well as proliferation of VSMCs [42]. In pulmonary artery smooth muscle cells obtained from patients with idiopathic pulmonary arterial hypertension, simvastatin inhibited translocation of RhoA to the membrane, migration of VSMCs and organization of actin fibers, all induced by the application of PDGF-BB [117]. In addition, pretreatment with pitavastatin inhibited PDGF-BB-induced VSMC-mediated collagen (type I) lattice contraction in a dose-dependent manner [118]. The lattice contraction was also inhibited by a C3 exoenzyme, a Rho inhibitor, and Y-27632. Thus, statins or inhibition of the Rho-ROCK pathway prevented PDGF-BB-induced proliferation of VSMCs and collagen lattice contraction.

Regarding the effect of statins on cerebral vasospasm, abrupt withdrawal of statins in the acute phase of SAH increased the risk of vasospasm significantly [119]. The administration of a statin prior to the onset of SAH significantly improved the 'no cerebral infarction' rate from 37 to $75 \%(n=60)$ [120] and significantly reduced the incidence of symptomatic vasospasm by elevenfold ( $\mathrm{n}=$ 115) [121].

Acute treatment with a statin also reduced the development of angiographic vasospasm from 43 to $10 \%$ ( $\mathrm{n}=$ 80) [122] and improved the 'absent DCI' rate from 40 to $74 \%(\mathrm{n}=39)$ [123]. Thus, statin treatment in the acute phase of SAH has come to the forefront of prevention of cerebral vasospasm [124], although systematic analysis of acute treatment with statin before 2010 did not lend statistically significant support to the idea that statins have a beneficial effect in preventing DCI or improving the outcomes of SAH patients [125].

\section{Other Antagonists of PDGF-BB Function for the Prevention of Cerebral Vasospasm}

Cilostazol (CZ), a selective inhibitor of type III phosphodiesterase in platelets or VSMCs which has antithrombotic properties [126], an inhibitory action on the progression of carotid intima-media thickness [127], and a protective action on endothelial cell functions [128], has been approved for the treatment of symptoms related to peripheral arterial occlusive disease and symptoms of in- 
termittent claudication and for the prevention of recurrent cerebral infarction in Japan [129]. CZ prevented experimental cerebral vasospasm [130-132] and also reduced moderate to severe vasospasm on angiogram from $42 \%$ in controls to $15 \%$ in the treated group in humans $(\mathrm{n}=50)$ [133].

The findings that locally applied CZ prevented intimal hyperplasia in post-artery graft stenosis and completely suppressed the expression of an extracellular matrix protein induced by PDGF-BB in rats [134] and that CZ inhibited high glucose-induced PDGF-BB production from human umbilical vein endothelial cells in a dose-dependent manner [135] indicate that $\mathrm{CZ}$ is an antagonist of PDGF-BB function and/or a suppressor of PDGF-BB production.

\section{Does Cerebral Vasospasm in Animal Models, Where There Are Earlier Peaks, Truly Represent Vasospasm in Humans?}

In the study of the pathophysiology of cerebral vasospasm, it is sometimes argued that peak development of cerebral vasospasm occurs earlier in experimental animals than in humans. Our response to this argument is that the peak simply depends on the body size of the animal; i.e. it occurs on the sixth to the eighth day in humans (body weight $70 \mathrm{~kg}$ ) [4], on the third day in canines (body weight 4-5 kg) [136], on the second day in rabbits (body weight $3 \mathrm{~kg}$ ) [79] and after $24 \mathrm{~h}$ in rats (body weight $0.3 \mathrm{~kg}$ ) [137], a finding similar to the tendencies seen in longevity and heart/respiration rates, which represent the rate of passage of biological time in individual species.

\section{Conclusion}

PDGF-BB matches all the criteria needed to qualify as a spasmogen. Figure 4 shows how the host defense cascade is activated by $\mathrm{SAH}$, arterial injury or risk factors for atherosclerosis. The cascades that lead to cerebral vasospasm and neointimal formation are initiated by activation of the thrombin/complement system, followed by secretion of PDGF-BB from platelets in the subarachnoid space, macrophages in and around the vascular wall and endothelial cells in the vascular wall. Prolonged contact with PDGF-BB upregulates PDGFR- $\beta$ in arterial walls, enhancing the reactivity of the arteries to PDGF-BB. Downstream of PDGFR- $\beta$, the Rho-ROCK, MAP kinase

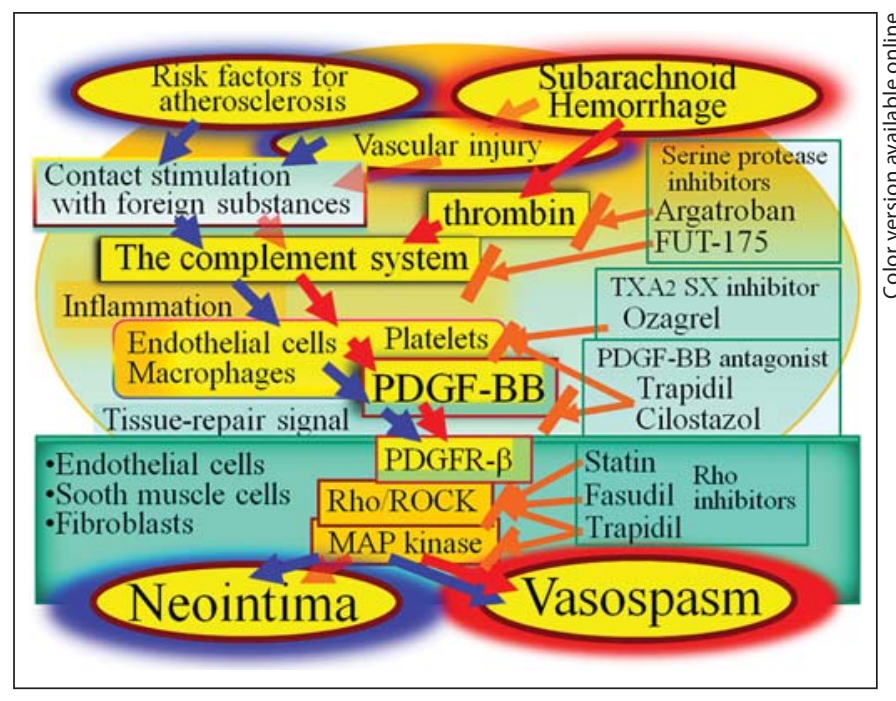

Fig. 4. Host defense/repair cascades activated by SAH, vascular injury or risk factors for atherosclerosis. The cascades that lead to the development of cerebral vasospasm or neointimal formation are triggered by thrombin and activation of the complement system, which stimulate the secretion of PDGF-BB for repair.

and tyrosine kinase pathways are activated, which results in the proliferation of VSMCs or persistent contraction of arteries, probably accompanied by compaction of the extracellular matrix.

Formation of a clot stimulates the production of PDGF-BB, which results in the development of cerebral vasospasm. PDGF-BB production is enhanced by arterial stretching injury during the formation of thick hematoma, brain edema and surgical manipulation. PDGF-BB production is beneficial for the repair of damaged cerebral arteries, by thickening arterial walls or contracting arteries to reduce regional cerebral blood flow and also for neuronal survival, but when it is excessive, DCI develops.

In studies that use an animal SAH model, inhibitory drugs can be administered with ideal timing, i.e. immediately after the induction of SAH, but in the clinical setting, the earliest drug administration usually starts no sooner than $12-24 \mathrm{~h}$ after onset. Because the activation of thrombin and the complement system peaks immediately after $\mathrm{SAH}$, the efficacy of these inhibitors must be significantly reduced if treatment is started after the peak. PDGF-BB produced in and around the arteries, coupled with upregulated PDGFR- $\beta$, is internalized in the VSMCs in the acute to subacute phase to activate identified and/ or unidentified intracellular cascades, leading to chronic contraction. 
In addition to the drugs already approved for the prevention of $\mathrm{DCI}$, serine protease inhibitors of the coagulation and complement cascade, inhibitors of PDGF-BB production and secretion, antagonists of PDGF-BB signal, inhibitors of PDGFR- $\beta$ and inhibitors downstream of PDGFR- $\beta$ activation are candidates for the treatment of cerebral vasospasm. Further investigation is needed to improve interventions that prevent or terminate the persistent phase of cerebral vasospasm.

\section{Acknowledgements}

We wish to acknowledge the valuable assistance and suggestions of Momosaki Nozomi, Machino Keiji, Bando Takemasa and Shiozuka Eri. This work was supported by the Japan Cardiovascular Research Foundation and Japan-China Sasakawa Medical fellowship.

\section{Disclosure Statement}

No conflicts of interest to declare.

\section{References}

1 Claassen J, Bernardini GL, Kreiter K, Bates J, Du YE, Copeland D, Connolly ES, Mayer SA: Effect of cisternal and ventricular blood on risk of delayed cerebral ischemia after subarachnoid hemorrhage: the Fisher scale revisited. Stroke 2001;32:2012-2020.

-2 Komotar RJ, Zacharia BE, Valhora R, Mocco J, Connolly ESJ: Advances in vasospasm treatment and prevention. J Neurol Sci 2007; 261:134-142.

- 3 Mocco J, Zacharia BE, Komotar RJ, Connolly ESJ: A review of current and future medical therapies for cerebral vasospasm following aneurysmal subarachnoid hemorrhage. Neurosurg Focus 2006;21:E9.

-4 Weir B, Grace M, Hansen J, Rothberg C: Time course of vasospasm in man. J Neurosurg 1978;48:173-178.

$\checkmark 5$ Macdonald RL, Weir BK: A review of hemoglobin and the pathogenesis of cerebral vasospasm. Stroke 1991;22:971-982.

-6 Weir B, Macdonald RL, Stoodley M: Etiology of cerebral vasospasm. Acta Neurochir Suppl (Wien) 1999;72:27-46.

-7 Harada T, Suzuki Y, Satoh S, Ikegaki I, Asano T, Shibuya M, Sugita K: Blood component induction of cerebral vasospasm. Neurosurgery 1990;27:252-255.

-8 Satoh S, Suzuki Y, Harada T, Ikegaki I, Asano T, Shibuya M, Sugita K, Saito A: The role of platelets in the development of cerebral vasospasm. Brain Res Bull 1991;27:663-668.

$\checkmark 9$ Peterson JW, Roussos L, Kwun BD, Hackett JD, Owen CJ, Zervas NT: Evidence of the role of hemolysis in experimental cerebral vasospasm. J Neurosurg 1990;72:775-781.

-10 Nozaki K, Okamoto S, Yanamoto H, Kikuchi $\mathrm{H}$ : Red blood cells are essential for late vasospasm following experimentally induced subarachnoid hemorrhage in dogs. Neurol Med Chir (Tokyo) 1990;30:10-15.

11 Brouwers PJ, Wijdicks EF, Van GJ: Infarction after aneurysm rupture does not depend on distribution or clearance rate of blood. Stroke 1992;23:374-379.

-12 Aoki T, Takenaka K, Suzuki S, Kassell NF, Sagher O, Lee KS: The role of hemolysate in the facilitation of oxyhemoglobin-induced contraction in rabbit basilar arteries. J Neurosurg 1994;81:261-266.

13 White RP, Macleod RM, Muhlbauer MS: Evaluation of the role hemoglobin in cerebrospinal fluid plays in producing contractions of cerebral arteries. Surg Neurol 1987; 27:237-242.

14 Kasuya H, Weir BK, White DM, Stefansson $\mathrm{K}$ : Mechanism of oxyhemoglobin-induced release of endothelin-1 from cultured vascular endothelial cells and smooth-muscle cells. J Neurosurg 1993;79:892-898.

15 Zimmermann M, Seifert V: Endothelin and subarachnoid hemorrhage: an overview. Neurosurgery 1998;43:863-876.

16 Pluta RM, Boock RJ, Afshar JK, Clouse K, Bacic M, Ehrenreich H, Oldfield EH: Source and cause of endothelin-1 release into cerebrospinal fluid after subarachnoid hemorrhage. J Neurosurg 1997;87:287-293.

-17 Hino A, Tokuyama Y, Kobayashi M, Yano M Weir B, Takeda J, Wang X, Bell GI, Macdonald RL: Increased expression of endothelin B receptor mRNA following subarachnoid hemorrhage in monkeys. J Cereb Blood Flow Metab 1996;16:688-697.

18 Fassbender K, Hodapp B, Rossol S, Bertsch T, Schmeck J, Schutt S, Fritzinger M, Horn P, Vajkoczy P, Wendel-Wellner M, Ragoschke A, Kuehl S, Brunner J, Schurer L, Schmiedeck P, Hennerici M: Endothelin-1 in subarachnoid hemorrhage: an acute-phase reactant produced by cerebrospinal fluid leukocytes. Stroke 2000;31:2971-2975.

19 Vajkoczy P, Meyer B, Weidauer S, Raabe A, Thome C, Ringel F, Breu V, Schmiedek P: Clazosentan (AXV-034343), a selective endothelin A receptor antagonist, in the prevention of cerebral vasospasm following severe aneurysmal subarachnoid hemorrhage: results of a randomized, double-blind, placebo-controlled, multicenter phase IIa study. J Neurosurg 2005;103:9-17.

-20 Macdonald RL, Higashida RT, Keller E, Mayer SA, Molyneux A, Raabe A, Vajkoczy P, Wanke I, Bach D, Frey A, Marr A, Roux S, Kassell N: Clazosentan, an endothelin receptor antagonist, in patients with aneurys- mal subarachnoid haemorrhage undergoing surgical clipping: a randomised, doubleblind, placebo-controlled phase 3 trial (CONSCIOUS-2). Lancet Neurol 2011;10: 618-625.

21 Sercombe R, Dinh YR, Gomis P: Cerebrovascular inflammation following subarachnoid hemorrhage. Jpn J Pharmacol 2002;88:227249.

22 Peterson JW, Kwun BD, Teramura A, Hackett JD, Morgan JA, Nishizawa S, Bun T, Zervas NT: Immunological reaction against the aging human subarachnoid erythrocyte. A model for the onset of cerebral vasospasm after subarachnoid hemorrhage. J Neurosurg 1989;71:718-726.

23 Peterson JW, Kwun BD, Hackett JD, Zervas NT: The role of inflammation in experimental cerebral vasospasm. J Neurosurg 1990;72: 767-774.

24 Yanamoto H, Kikuchi H, Okamoto S, Nozaki K: Cerebral vasospasm caused by cisternal injection of polystyrene latex beads in rabbits is inhibited by a serine protease inhibitor. Surg Neurol 1994;42:374-381.

25 Yanamoto H, Kikuchi H, Ishikawa J, Shimizu Y, Sato M, Tokuriki Y, Okamoto S, Matsumoto M, Matsumoto K, Nakamura K: Intravenous FUT-175 inhibits complement activation in the cerebrospinal fluid and vasospasm-related delayed ischemic neurological deficit following subarachnoid hemorrhage; in Findlay JM (ed): Cerebral Vasospasm: Proceedings of the Vth International Conference on Cerebral Vasospasm, Edmonton and Jasper, Alberta, Canada, May 17-21, 1993. Amsterdam, Elsevier, 1993, pp 431-434

26 Ross R, Masuda J, Raines EW, Gown AM, Katsuda S, Sasahara M, Malden LT, Masuko $\mathrm{H}$, Sato H: Localization of PDGF-B protein in macrophages in all phases of atherogenesis. Science 1990;248:1009-1012.

27 Seifert PS, Hugo F, Tranum-Jensen J, Zahringer $\mathrm{U}$, Muhly $\mathrm{M}$, Bhakdi S: Isolation and characterization of a complement-activating lipid extracted from human atherosclerotic lesions. J Exp Med 1990;172:547-557. 
-28 Oksjoki R, Kovanen PT, Pentikäinen MO: Role of complement activation in atherosclerosis. Curr Opin Lipidol 2003; 14:477-482.

-29 Andrae J, Gallini R, Betsholtz C: Role of platelet-derived growth factors in physiology and medicine. Genes Dev 2008;22:1276-1312.

>30 Torzewski M, Klouche M, Hock J, Messner M, Dorweiler B, Torzewski J, Gabbert HE, Bhakdi S: Immunohistochemical demonstration of enzymatically modified human LDL and its colocalization with the terminal complement complex in the early atherosclerotic lesion. Arterioscler Thromb Vasc Biol 1998;18:369-378.

-31 Ross R, Vogel A: The platelet-derived growth factor. Cell 1978;14:203-210.

-32 Wagsater D, Zhu C, Bjorck HM, Eriksson P: Effects of PDGF-C and PDGF-D on monocyte migration and MMP-2 and MMP-9 expression. Atherosclerosis 2009;202:415-423.

33 Raines EW, Bowen-Pope DF, Ross R: Platelet-derived growth factor; in Sporn MB, Roberts $\mathrm{AB}$ (eds): Handbook of Experimental Pharmacology: Peptide Growth Factors and Their Receptors. Berlin, Springer, 1990, vol 95/I, pp 173-262.

-34 Iihara K, Sasahara M, Hashimoto N, Uemura Y, Kikuchi H, Hazama F: Ischemia induces the expression of platelet-derived growth factor-B chain in neurons and brain macrophages in vivo. J Cereb Blood Flow Metab 1994; $14: 818-824$.

- 35 Smits A, Hermansson M, Nistér M, Karnushina I, Heldin CH, Westermark B, Funa $\mathrm{K}$ : Rat brain capillary endothelial cells express functional PDGF B-type receptors. Growth Factors 1989;2:1-8.

-36 Smits A, Ballagi AE, Funa K: PDGF-BB exerts trophic activity on cultured GABA interneurons from the newborn rat cerebellum. Eur J Neurosci 1993;5:986-994.

-37 Smits A, Kato M, Westermark B, Nistér M, Heldin CH, Funa K: Neurotrophic activity of platelet-derived growth factor (PDGF): rat neuronal cells possess functional PDGF $\beta$ type receptors and respond to PDGF. Proc Natl Acad Sci USA 1991;88:8159-8163.

-38 Savikko J, von Willebrand E: Coexpression of platelet-derived growth factors AA and BB and their receptors during monocytic differentiation. Transplant Proc 2001;33:23072308.

-39 Iihara K, Sasahara M, Hashimoto N, Hazama F: Induction of platelet-derived growth factor $\beta$-receptor in focal ischemia of rat brain. J Cereb Blood Flow Metab 1996;16: 941-949.

-40 Sakata M, Yanamoto H, Hashimoto N, Iihara K, Tsukahara T, Taniguchi T, Kikuchi $\mathrm{H}$ : Induction of infarct tolerance by plateletderived growth factor against temporary focal ischemia. Brain Res 1998;784:250-255.

-41 Iihara K, Hashimoto N, Tsukahara T, Sakata M, Yanamoto H, Taniguchi T: Platelet-derived growth factor-BB, but not -AA, prevents delayed neuronal death after forebrain ischemia in rats. J Cereb Blood Flow Metab 1997; 17:1097-1106.
42 Kamiyama M, Utsunomiya K, Taniguchi K, Yokota T, Kurata H, Tajima N, Kondo K: Contribution of Rho $\mathrm{A}$ and Rho kinase to platelet-derived growth factor-BB-induced proliferation of vascular smooth muscle cells. J Atheroscler Thromb 2003;10:117-123.

43 Sawada N, Itoh H, Ueyama K, Yamashita J, Doi K, Chun TH, Inoue M, Masatsugu K, Saito T, Fukunaga Y, Sakaguchi S, Arai H, Ohno N, Komeda M, Nakao K: Inhibition of rho-associated kinase results in suppression of neointimal formation of balloon-injured arteries. Circulation 2000;101:2030-2033.

44 Shibata R, Kai H, Seki Y, Kato S, Morimatsu M, Kaibuchi K, Imaizumi T: Role of Rho-associated kinase in neointima formation after vascular injury. Circulation 2001;103:284289.

45 Rubin K, Tingström A, Hansson GK, Larsson E, Rönnstrand L, Klareskog L, ClaessonWelsh L, Heldin CH, Fellström B, Terracio L: Induction of B-type receptors for plateletderived growth factor in vascular inflammation: possible implications for development of vascular proliferative lesions. Lancet 1988 1:1353-1356.

46 Wilcox JN, Smith KM, Williams LT, Schwartz SM, Gordon D: Platelet-derived growth factor mRNA detection in human atherosclerotic plaques by in situ hybridization. J Clin Invest 1988;82:1134-1143.

$\checkmark 47$ Huwiler A, Fabbro D, Pfeilschifter J: Plateletderived growth factor stimulates de-novo synthesis of mitogen-activated protein kinase in renal mesangial cells. Eur J Biochem 1995;227:209-213.

48 Benzaquen LR, Nicholson-Weller A, Halperin JA: Terminal complement proteins C5b-9 release basic fibroblast growth factor and platelet-derived growth factor from endothelial cells. J Exp Med 1994;179:985-992.

49 Lappegård KT, Bergseth G, Riesenfeld J, Pharo A, Magotti P, Lambris JD, Mollnes TE: The artificial surface-induced whole blood inflammatory reaction revealed by increases in a series of chemokines and growth factors is largely complement dependent. J Biomed Mater Res A 2008;87:129-135.

50 Buono C, Come CE, Witztum JL, Maguire GF, Connelly PW, Carroll M, Lichtman AH: Influence of C3 deficiency on atherosclerosis. Circulation 2002;105:3025-3031.

51 Yasojima K, Schwab C, McGeer EG, McGeer PL: Generation of C-reactive protein and complement components in atherosclerotic plaques. Am J Pathol 2001;158:1039-1051.

52 Nagata I, Zhang Z, Sawada M, Hashimoto N, Kikuchi H, Yanamoto H: Systemically administered thrombin inhibitors can prevent neointimal formation and cerebral vasospasm: the possible role of thrombin and PDGF-BB in vascular pathogeneses; in Kikuchi H (ed): Strategic Medical Science Against Brain Attack. Tokyo, Springer, 2002, pp 234-253.

53 Badgett A, Bonner JC, Brody AR: Interferongamma modulates lung macrophage production of PDGF-BB and fibroblast growth J Lipid Mediat Cell Signal 1996;13:89-97.
54 Bohm M, Blasius S, Roessner A: Immunohistochemical localization of PDGF B, PDGF beta receptors and IGF I receptors during atherogenesis. Zentralbl Pathol 1994;140: 357-362.

55 Ikari N, Sakai Y, Hitomi Y, Fujii S: New synthetic inhibitor to the alternative complement pathway. Immunology 1983;49:685691.

56 Fujii S, Hitomi Y: New synthetic inhibitors of C1r, C1 esterase, thrombin, plasmin, kallikrein and trypsin. Biochim Biophys Acta 1981;661:342-345.

57 Hitomi Y, Fujii S: Inhibition of various immunological reactions in vivo by a new synthetic complement inhibitor. Int Arch Allergy Appl Immunol 1982;69:262-267.

-58 Sawada M, Yanamoto H, Nagata I, Hashimoto N, Nakahara I, Akiyama Y, Kikuchi H: Prevention of neointimal formation by a serine protease inhibitor, FUT-175, after carotid balloon injury in rats. Stroke 1999;30:644650.

59 Ko SB, Choi HA, Carpenter AM, Helbok R, Schmidt JM, Badjatia N, Claassen J, Connolly ES, Mayer SA, Lee K: Quantitative analysis of hemorrhage volume for predicting delayed cerebral ischemia after subarachnoid hemorrhage. Stroke 2011;42:669-674.

60 Rinkel GJ, Wijdicks EF, Vermeulen M, Hasan D, Brouwers PJ, Van GJ: The clinical course of perimesencephalic nonaneurysmal subarachnoid hemorrhage. Ann Neurol 1991;29:463-468.

61 Kasuya H, Shimizu T: Activated complement components $\mathrm{C} 3 \mathrm{a}$ and $\mathrm{C} 4 \mathrm{a}$ in cerebrospinal fluid and plasma following subarachnoid hemorrhage. J Neurosurg 1989;71:741-746.

62 Mack WJ, Ducruet AF, Hickman ZL, Garrett MC, Albert EJ, Kellner CP, Mocco J, Connolly ESJ: Early plasma complement C3a levels correlate with functional outcome after aneurysmal subarachnoid hemorrhage. Neurosurgery 2007;61:255-260.

63 Nagata K, Sasaki T, Mori T, Nikaido H, Kobayashi E, Kim P, Kirino T: Cisternal talc injection in dog can induce delayed and prolonged arterial constriction resembling cerebral vasospasm morphologically and pharmacologically. Surg Neurol 1996;45: 442-447.

64 Mori T, Nagata K, Ishida T, Nikaido H, Kobayashi E, Sasaki T, Ohami H, Kirino T: Sequential morphological changes of the constrictive basilar artery in a canine model of experimental cerebral vasospasm by talc injection. J Vet Med Sci 1994;56:535-540.

65 Recinos PF, Pradilla G, Thai QA, Perez M, Hdeib AM, Tamargo RJ: Controlled release of lipopolysaccharide in the subarachnoid space of rabbits induces chronic vasospasm in the absence of blood. Surg Neurol 2006;66: 463-469.

66 German JW, Gross CE, Giclas P, Watral W, Bednar MM: Systemic complement depletion inhibits experimental cerebral vasospasm. Neurosurgery 1996;39:141-145. 
-67 Clatterbuck RE, Gailloud P, Ogata L, Gebremariam A, Dietsch GN, Murphy KJ, Tamargo RJ: Prevention of cerebral vasospasm by a humanized anti-CD11/CD18 monoclonal antibody administered after experimental subarachnoid hemorrhage in nonhuman primates. J Neurosurg 2003;99:376-382.

68 Yanamoto H, Kikuchi H, Okamoto S: Effects of protease inhibitor and immunosuppressant on cerebral vasospasm after subarachnoid hemorrhage in rabbits. Surg Neurol 1994;42:382-387.

69 Nagata K, Sasaki T, Mori T, Ooami H, Nirei H, Hamada K, Kirino T: Both cyclosporine A and FK-506 failed to prevent cerebral vasospasm in canine two hemorrhage model; in Findlay JM (ed): Cerebral Vasospasm: Proceedings of the Vth International Conference on Cerebral Vasospasm, Edmonton and Jasper, Alberta, Canada, May 17-21, 1993. Amsterdam, Elsevier, 1993, pp 439-442.

70 Gaetani P, Tancioni F, Grignani G, Tartara F, Merlo EM, Brocchieri A, Rodriguez y Baena $\mathrm{R}$ : Platelet derived growth factor and subarachnoid haemorrhage: a study on cisternal cerebrospinal fluid. Acta Neurochir (Wien) 1997;139:319-324.

-71 Maeda Y, Hirano K, Hirano M, Kikkawa Y, Kameda K, Sasaki T, Kanaide H: Enhanced contractile response of the basilar artery to platelet-derived growth factor in subarachnoid hemorrhage. Stroke 2009;40:591-596.

-72 Zhang Z, Nagata I, Kikuchi H, Xue JH, Sakai $\mathrm{N}$, Sakai H, Yanamoto H: Broad-spectrum and selective serine protease inhibitors prevent expression of platelet-derived growth factor-BB and cerebral vasospasm after subarachnoid hemorrhage: vasospasm caused by cisternal injection of recombinant platelet-derived growth factor-BB. Stroke 2001;32:1665-1672.

-73 Sachinidis A, Locher R, Hoppe J, Vetter W: The platelet-derived growth factor isomers, PDGF-AA, PDGF-AB and PDGF-BB, induce contraction of vascular smooth muscle cells by different intracellular mechanisms. FEBS Lett 1990;275:95-98.

-74 Berk BC, Alexander RW, Brock TA, Gimbrone MA Jr, Webb RC: Vasoconstriction: a new activity for platelet-derived growth factor. Science 1986;232:87-90.

75 Bassett JE, Bowen-Pope DF, Takayasu M, Dacey RG Jr: Platelet-derived growth factor does not constrict rat intracerebral arterioles in vitro. Microvasc Res 1988;35:368-373.

76 Miller CA, Lombard FW, Wu CT, Hubbard CJ, Silbajoris L, Borel CO, Niklason LE: Role of vascular mitogens in subarachnoid hemorrhage-associated cerebral vasculopathy. Neurocrit Care 2006;5:215-221.

-77 Zhang ZW, Yanamoto H, Nagata I, Miyamoto S, Nakajo Y, Xue JH, Iihara K, Kikuchi H: Platelet-derived growth factor-induced severe and chronic vasoconstriction of cerebral arteries: proposed growth factor explanation of cerebral vasospasm. Neurosurgery 2010;66:728-735.
78 Claesson-Welsh L: Platelet-derived growth factor receptor signals. J Biol Chem 1994, 269:32023-32026.

79 Yanamoto H, Kikuchi H, Okamoto S, Nozaki K: Preventive effect of synthetic serine protease inhibitor, FUT-175, on cerebral vasospasm in rabbits. Neurosurgery 1992;30: 351-357.

80 Yanamoto H, Kikuchi H, Sato M, Shimizu Y, Yoneda S, Okamoto S: Therapeutic trial of cerebral vasospasm with the serine protease inhibitor, FUT-175, administered in the acute stage after subarachnoid hemorrhage. Neurosurgery 1992;30:358-363.

81 Kaminogo M, Yonekura M, Onizuka M, Yasunaga A, Shibata S: Combination of serine protease inhibitor FUT-175 and thromboxane synthetase inhibitor OKY-046 decreases cerebral vasospasm in patients with subarachnoid hemorrhage. Neurol Med Chir (Tokyo) 1998;38:704-709.

82 Shuman MA: Thrombin-cellular Interactions. Ann NY Acad Sci 1986;485:228-239.

83 Narayanan S: Multifunctional roles of thrombin. Ann Clin Lab Sci 1999;29:275280.

84 Chen LB, Buchanan JM: Mitogenic activity of blood components. 1. Thrombin and prothrombin. Proc Natl Acad Sci USA 1975;72: 131-135.

85 Tsurutani H, Ohkuma H, Suzuki S: Effects of thrombin inhibitor on thrombin-related signal transduction and cerebral vasospasm in the rabbit subarachnoid hemorrhage model. Stroke 2003;34:1497-1500.

86 Suzuki M, Otawara Y, Kuto A, Yoshida K, Kubo Y, Doi M, Ogasawara K, Suzuki T, Kuroda K, Ogawa A: Prophylactic effect of argatroban for vasospasm following subarachnoid hemorrhage. Proceedings of the 14th Spasm Symposium, Kyoto, 1988, pp 350-353.

-87 Kasuya H, Shimizu T, Takakura K: Thrombin activity in CSF after SAH is correlated with the degree of SAH the persistence of subarachnoid clot and the development of vasospasm. Acta Neurochir (Wien) 1998; 140:579-584.

88 Jerius H, Beall A, Woodrum D, Epstein A, Brophy C: Thrombin-induced vasospasm: cellular signaling mechanisms. Surgery 1998;123:46-50.

89 Nelken NA, Soifer SJ, O'keefe J, Vu TKH, Charo IF, Coughlin SR: Thrombin receptor expression in normal and atherosclerotic human arteries. J Clin Invest 1992;90:16141621.

90 Maeda Y, Hirano K, Kai Y, Hirano M, Suzuki SO, Sasaki T, Kanaide H: Up-regulation of proteinase-activated receptor 1 and increased contractile responses to thrombin after subarachnoid haemorrhage. Br J Pharmacol 2007;152:1131-1139.

-91 Hirashima Y, Nakamura S, Suzuki M, Kurimoto M, Endo S, Ogawa A, Kakaku A: Cerebrospinal fluid tissue factor and thrombinantithrombin III complex as indicators of tissue injury after subarachnoid hemorrhage. Stroke 1997;28:1666-1670.
-92 Kameda K, Kikkawa Y, Hirano M, Matsuo S, Sasaki T, Hirano K: Combined argatroban and anti-oxidative agents prevents increased vascular contractility to thrombin and other ligands after subarachnoid hemorrhage. Br J Pharmacol 2012;165:106-119.

-93 Liao JK, Seto M, Noma K: Rho kinase (ROCK) inhibitors. J Cardiovasc Pharmacol 2007;50:17-24.

94 Shimokawa H, Rashid M: Development of Rho-kinase inhibitors for cardiovascular medicine. Trends Pharmacol Sci 2007;28: 296-302.

-95 Shimokawa H, Seto M, Katsumata N, Amano M, Kozai T, Yamawaki T, Kuwata K, Kandabashi T, Egashira K, Ikegaki I, Asano T, Kaibuchi K, Takeshita A: Rho-kinasemediated pathway induces enhanced myosin light chain phosphorylations in a swine model of coronary artery spasm. Cardiovasc Res 1999;43:1029-1039.

-96 Miyagi Y, Carpenter RC, Meguro T, Parent $\mathrm{AD}$, Zhang JH: Upregulation of rho A and rho kinase messenger RNAs in the basilar artery of a rat model of subarachnoid hemorrhage. J Neurosurg 2000;93:471-476.

97 Sato M, Tani E, Fujikawa H, Kaibuchi K: Involvement of Rho-kinase-mediated phosphorylation of myosin light chain in enhancement of cerebral vasospasm. Circ Res 2000;87:195-200.

-98 Sasaki T, Kasuya H, Onda H, Sasahara A, Goto S, Hori T, Inoue I: Role of p38 mitogen-activated protein kinase on cerebral vasospasm after subarachnoid hemorrhage. Stroke 2004;35:1466-1470.

-99 Watts EJ, Rose MT: Platelet-derived growth factor acts via both the Rho-kinase and p38 signaling enzymes to stimulate contraction in an in vitro model of equine wound healing. Domest Anim Endocrinol 2010;38: 253-259.

100 Iwasa K, Bernanke DH, Smith RR, Yamamoto Y: Nonmuscle arterial constriction after subarachnoid hemorrhage: role of growth factors derived from platelets. Neurosurgery 1993;32:619-624.

101 Onoda K, Ono S, Ogihara K, Shiota T, Asari S, Ohmoto T, Ninomiya Y: Role of extracellular matrix in experimental vasospasm. Inhibitory effect of antisense oligonucleotide on collagen induction. Stroke 1996; 27:2102-2108.

102 Suzuki Y, Yamaguchi K, Shimada S, Kitamura Y, Ohnishi H: Antithrombotic activity and the mecahnism of action of trapidil (Rocornal). Prostaglandins Leukot Med 1982;9:685-695.

103 Hirayama A, Kodama K, Yui Y, Nonogi H, Sumiyoshi T, Origasa H, Hosoda S, Kawaim C: Effect of trapidil on cardiovascular events in patients with coronary artery disease (results from the Japan Multicenter Investigation for Cardiovascular DiseasesMochida [JMIC-M]). Am J Cardiol 2003; 92:789-793. 
104 Hoshiya M, Awazu M: Trapidil inhibits platelet-derived growth factor-stimulated mitogen-activated protein kinase cascade. Hypertension 1998;31:665-671.

-105 Gesualdo L, Di Paolo S, Ranieri E, Schena FP: Trapidil inhibits human mesangial cell proliferation: effect on PDGF b-receptor binding and expression. Kidney Int 1994; 46:1002-1009.

106 Ishikura K, Fujita H, Hida M, Awazu M: Trapidil inhibits platelet-derived growth factor-induced migration via protein $\mathrm{ki}$ nase $\mathrm{A}$ and RhoA/Rho-associated kinase in rat vascular smooth muscle cells. Eur J Pharmacol 2005;515:28-33.

107 Suzuki S, Sobata E, Iwabuchi T: Prevention of cerebral ischemic symptoms in cerebral vasospasm with trapidil, an antagonist and selective synthesis inhibitor of thromboxane A2. Neurosurgery 1981;9:679-685.

-108 Iwabuchi S, Yokouchi T, Hayashi M, Uehara $\mathrm{H}$, Ueda M, Samejima H: Intra-arterial administration of fasudil hydrochloride for vasospasm following subarachnoid hemorrhage - analysis of time-density curve with digital subtraction angiography. Neurol Med Chir (Tokyo) 2006;46:535-539.

-109 Sibuya M, Suzuki Y, Sugita K, Saito I, Sasaki T, Takakura K, Nagata I, Kikuchi H, Takemae T, Hidaka H, Nakashima M: Effect of AT877 on cerebral vasospasm after aneurysmal subarachnoid hemorrhage. Results of a prospective placebo-controlled double-blind trial. J Neurosurg 1992;76: 571-577.

110 Suzuki Y, Shibuya M, Satoh S, Sugimoto Y, Takakura K: A postmarketing surveillance study of fasudil treatment after aneurysmal subarachnoid hemorrhage. Surg Neurol 2007;68:126-131.

-111 Nagumo H, Sasaki Y, Ono Y, Okamoto H, Seto M, Takuwa Y: Rho kinase inhibitor HA-1077 prevents Rho-mediated myosin phosphatase inhibition in smooth muscle cells. Am J Physiol Cell Physiol 2000; 278:C57-C65.

-112 Suzuki Y, Shibuya M, Satoh S, Sugiyama H, Seto M, Takakura K: Safety and efficacy of fasudil monotherapy and fasudil-ozagrel combination therapy in patients with subarachnoid hemorrhage: sub-analysis of the post-marketing surveillance study. Neurol Med Chir (Tokyo) 2008;48:241-247.

113 Ono K, Shirotani T, Wada K, Takahara T, Matsushita Y, Yuba K, Yamana D: Intra-arterial administration of fasudil hydrochloride: duration of action (in Japanese). No Shinkei Geka 2005;33:133-140.

114 Anei R, Iihara K, Yanamoto H, Zhang Z, Higashi T, Murao K, Kogure S, Takahashi J, Hayashi K, Nagamine T, Ishibashi T, Soeda A, Taniguchi A, Fukuda H, Fukui N, Nagata I: Treatment for cerebral vasospasm with nonselective serine protease inhibitor, FUT-175 and selective serine protease inhibitor for thrombin, argatroban. Surgery Cerebral Stroke (Japanese) 2002;30 (suppl):88-91.
115 Shaw SM, Fildes JE, Yonan N, Williams SG: Pleiotropic effects and cholesterol-lowering therapy. Cardiology 2008;112:4-12.

116 Zhou Q, Liao JK: Rho kinase: an important mediator of atherosclerosis and vascular disease. Curr Pharm Des 2009;15:3108-3115.

117 Ikeda T, Nakamura K, Akagi S, Kusano KF, Matsubara H, Fujio H, Ogawa A, Miura A, Miura D, Oto T, Yamanaka R, Otsuka F, Date $\mathrm{H}$, Ohe $\mathrm{T}$, Ito $\mathrm{H}$ : Inhibitory effects of simvastatin on platelet-derived growth factor signaling in pulmonary artery smooth muscle cells from patients with idiopathic pulmonary arterial hypertension. J Cardiovasc Pharmacol 2010;55:39-48.

118 Kuzuya M, Cheng XW, Sasaki T, TamayaMori N, Iguchi A: Pitavastatin, a 3-hydroxy3-methylglutaryl-coenzyme A reductase inhibitor, blocks vascular smooth muscle cell populated-collagen lattice contraction. J Cardiovasc Pharmacol 2004;43:808-814.

119 Singhal AB, Topcuoglu MA, Dorer DJ, Ogilvy CS, Carter BS, Koroshetz WJ: SSRI and statin use increases the risk for vasospasm after subarachnoid hemorrhage. Neurology 2005;64:1008-1013.

120 Parra A, Kreiter KT, Williams S, Sciacca R, Mack WJ, Naidech AM, Commichau CS, Fitzsimmons BF, Janjua N, Mayer SA, Connolly ES Jr: Effect of prior statin use on functional outcome and delayed vasospasm after acute aneurysmal subarachnoid hemorrhage: a matched controlled cohort study. Neurosurgery 2005;56:476-484.

121 McGirt MJ, Blessing R, Alexander MJ, Nimjee SM, Woodworth GF, Friedman $\mathrm{AH}$ Graffagnino C, Laskowitz DT, Lynch JR: Risk of cerebral vasopasm after subarachnoid hemorrhage reduced by statin therapy: a multivariate analysis of an institutional experience. J Neurosurg 2006;105:671-674.

122 Tseng MY, Czosnyka M, Richards H, Pickard JD, Kirkpatrick PJ: Effects of acute treatment with pravastatin on cerebral vasospasm, autoregulation, and delayed ischemic deficits after aneurysmal subarachnoid hemorrhage: a phase II randomized placebo-controlled trial. Stroke 2005;36:1627-1632.

123 Lynch JR, Wang H, McGirt MJ, Floyd J, Friedman AH, Coon AL, Blessing R, Alexander MJ, Graffagnino C, Warner DS, Laskowitz DT: Simvastatin reduces vasospasm after aneurysmal subarachnoid hemorrhage: results of a pilot randomized clinical trial. Stroke 2005;36:2024-2026.

124 Trimble JL, Kockler DR: Statin treatment of cerebral vasospasm after aneurysmal subarachnoid hemorrhage. Ann Pharmacother 2007;41:2019-2023.

125 Vergouwen MD, de Haan RJ, Vermeulen M, Roos YB: Effect of statin treatment on vasospasm, delayed cerebral ischemia, and functional outcome in patients with aneurysmal subarachnoid hemorrhage: a systematic review and meta-analysis update. Stroke 2010;41:e47-e52.

126 Kambayashi J, Liu Y, Sun B, Shakur Y, Yoshitake M, Czerwiec F: Cilostazol as a unique antithrombotic agent. Curr Pharm Des 2003;9:2289-2302.

127 Katakami N, Kim YS, Kawamori R, Yamasaki Y: The phosphodiesterase inhibitor cilostazol induces regression of carotid atherosclerosis in subjects with type 2 diabetes mellitus: principal results of the Diabetic Atherosclerosis Prevention by Cilostazol (DAPC) study: a randomized trial. Circulation 2010;121:2584-2591.

128 Oyama N, Yagita Y, Kawamura M, Sugiyama Y, Terasaki Y, Omura-Matsuoka E, Sasaki T, Kitagawa K: Cilostazol, not aspirin, reduces ischemic brain injury via endothelial protection in spontaneously hypertensive rats. Stroke 2011;42:2571-2577.

129 Uchiyama S, Demaerschalk BM, Goto S, Shinohara Y, Gotoh F, Stone WM, Money SR, Kwon SU: Stroke prevention by cilostazol in patients with atherothrombosis: meta-analysis of placebo-controlled randomized trials. J Stroke Cerebrovasc Dis 2009;18:482-490

130 Yamaguchi-Okada M, Nishizawa S, Mizutani A, Namba H: Multifaceted effects of selective inhibitor of phosphodiesterase III, cilostazol, for cerebral vasospasm after subarachnoid hemorrhage in a dog model. Cerebrovasc Dis 2009;28:135-142.

131 Nishino A, Umegaki M, Fujinaka T, Yoshimine T: Cilostazol attenuates cerebral vasospasm after experimental subarachnoid hemorrhage. Neurol Res 2010;32:873-878.

132 Ito H, Fukunaga M, Suzuki H, Miyakoda G, Ishikawa M, Yabuuchi Y, Taki W: Effect of cilostazol on delayed cerebral vasospasm after subarachnoid hemorrhage in rats: evaluation using black blood magnetic resonance imaging. Neurobiol Dis 2008;32:157-161.

133 Yoshimoto T, Shirasaka T, Fujimoto S, Yoshidumi T, Yamauchi T, Tokuda K, Kaneko S, Kashiwaba T: Cilostazol may prevent cerebral vasospasm following subarachnoid hemorrhage. Neurol Med Chir (Tokyo) 2009;49:235-240.

134 Fujinaga K, Onoda K, Yamamoto K, Imanaka-Yoshida K, Takao M, Shimono T, Shimpo H, Yoshida T, Yada I: Locally applied cilostazol suppresses neointimal hyperplasia by inhibiting tenascin-C synthesis and smooth muscle cell proliferation in free artery grafts. J Thorac Cardiovasc Surg 2004; 128:357-363.

135 Mizutani M, Okuda Y, Yamashita K: Effect of cilostazol on the production of plateletderived growth factor in cultured human vascular endothelial cells. Biochem $\mathrm{Mol}$ Med 1996;57:156-158.

136 Nozaki K, Okamoto S, Uemura Y, Yanamoto H, Kikuchi H: Changes of glycogen and ATP contents of the major cerebral arteries after experimentally produced subarachnoid haemorrhage in the dog. Acta Neurochir (Wien) 1990;104:38-41.

137 Suzuki H, Hasegawa Y, Chen W, Kanamaru $\mathrm{K}$, Zhang JH: Recombinant osteopontin in cerebral vasospasm after subarachnoid hemorrhage. Ann Neurol 2010;68:650-660. 